\title{
The Politics of Post-9/11 Music: Sound, Trauma, and the Music Industry in the Time of Terror
}

\author{
Joseph P. Fisher and Brian Flota (Eds) \\ Farnham, Surrey, UK: Ashgate, 2011 \\ ISBN: $9781409427841(\mathrm{HB})$ \\ RRP: \$99.95 (USD)
}

\author{
Bruce Johnson \\ University of Turku, Finland \\ Bruce.Johnson@utu.fi
}

It would squander space to list the contents of this collection, since they and the Introduction can be read online at:

http://www.ashgate.com/default.aspx?page $=637 \&$ calctitle $=1 \&$ pageSubject $=414 \&$ title id=10895\&edition id=14358.

Given the hydra head of the music industry it is gratifying to see such a collection bringing a cross-disciplinary perspective that appears to go beyond academic to professional and journalistic discourses. Inevitably, the result is a curate's egg. In spite of the words 'Post 9/11 Music' in the title, much of this collection is not really about music developments that postdate 9/11 and which might be considered to have been caused by that appalling event. The subtitle's phrase 'in the age of terror' opens more historical leeway, if at the expense of precision - there have after all been other 'ages of terror', a circumstance rather elided in the use of the exceptionalist and solipsistic definite article. Of this, more below.

Among the most instructive chapters are those which address changes in media technologies and music, largely the brief of the three chapters in Part 1 . While there is no evidence that these changes would not have proceeded without $9 / 11$, it is certainly arguable that they are linked closely to, or deployed in the service of, a public anxiety increased dramatically by that event, as for example the production of the video game America's Army. When we turn to the contemporary sensibilities, what might be called the 'mentalité' of the 'age of terror' however, there seems to be rather tenuous evidence of profound changes. 9/11 itself is not actually pivotal in many of the developments that are discussed, which were responses to other events both before and after, such as musical interventions in the Bush election campaign of 2004 (Rock Against Bush); that is, responses not to $9 / 11$ but to the incompetence of Bush's responses to it. Or they were forms of consciousness and practice that in fact predated 2001, such as disillusionment with what may be called the American Dream (see early twentieth century writers like Fitzgerald and West, as well as a very extensive library of US popular song). For example, the emergence of goth-punk, for which the claim that it manifests "a generational loss of innocence caused by the war on terror" (2011: 150), seems clearly anachronistic. Similarly, the militarisation of everyday life referred to in Chapter 1 certainly did not begin post-2001, but characterised many 
regimes from ancient times (Sparta) to, for example, the Third Reich. Likewise, the suggestion that "the first example of the hybridization of music video and military recruitment" (14) was the video "Citizen/Soldier" (14) is simply a statement about the application of a modern technology to an ancient nexus. Music has always accompanied recruitment campaigns; even the Pied Piper was almost certainly a member of a special cadre of military recruiters using theatrical costumes and music. The discussion of the "technostalgic" re-emergence of cassette technology (43-56) was fascinating. But the author himself dates the trend from 1995, and while it might have acquired a new resonance after 2001, it was hardly a product of it. There is also an argument that the first word in Improvised Explosive Device - IED - (instead of, for example "home-made") reflects a negative valency that links it to the suspicion in which jazz was once held, because they are both associated with subversion (yet we are also told that a US military slogan is "adapt, improvise, overcome"). But the author also notes that the first use of the term IED was at least as far back as 1940, so it is not clear how an event in 2001 is seminal here. That valency incidentally is allegedly fortified by the fact that the Twin Towers was "from a conventional viewpoint an improvisational" (80) attack, though five lines later it is described as "carefully planned". I know of no evidence that it was ever seriously regarded otherwise.

This is really a collection of essays, many of them extremely instructive, on aspects of popular music in the twenty-first century (and sometimes much earlier). And as someone who has extensively researched and published on music and trauma, I was surprised at how little reference was made to the latter, given the title. Sometimes 9/11 and its consequences do provide a persuasive hook to hang them on, as in Kathryn Wright's discussion of Nine Inch Nails and the Patriot Act. Also outstanding are Steve Waksman's detailed and judicious analysis of the use of heavy metal in films about the war in Iraq and Gerritt Roessler's discussion of Christian punk rock in its aftermath convincingly traces a shift in consciousness, using the band Underoath as a case study. It is interesting that these studies are anchored securely in specific texts, which act as a check, in all senses, on generalisation and hyperbole. And it is equally of interest that one of the conclusions arising from Roessler's study, and also to a significant extent from those of Jeffrey Roessner and Matthew Siblo on punk and indie rock, is that pop largely failed to register $9 / 11(115-6,129)$. Maybe here is the answer to the question of why the focus of this collection is so diffuse in relation to the event its title centralises. As Roessler suggests, "The established cultural and political institutions failed to create a homogenous response to $9 / 11$ precisely because homogeneity is not a quality of mainstream culture" (181).

It is as though mainstream US culture no longer seems to be able to draw on the kind of fully agreed history that produces something approaching the national consciousness that appears to unite a community in the face of real or assumed adversity - like Germany from the mid-1930s or Britain or the US during WW2. Mention of the lack of a sense of history, a cultural solipsism, takes me back to the opening comments. I certainly do not want to make the absurd claim that because there have been worse things than 9/11 we should not be talking about it. It did have an impact that requires notice. My difficulty lies with the frequent absence of perspective which leads to misleading and ahistorical claims and generalisations. Apart from examples already cited, the claims that if music is not online in the 21st century "it does not exist for popular culture" (31), and that "music is no longer centred in itself, but rather in the device on which it plays" (41) overlook the massive amount of live music-making that takes place every day - and who are those people making and listening to music on videos of concerts on Youtube? This is what I mean by solipsism - the mistaken assumption that the world is comprehended fully within my own wired up horizons. To exemplify, in 2006 I had reason to discover that since the introduction of the iPod in 2001, market leader Apple has shipped in excess of thirty million units. The figure is 
impressive, until it is remembered that this represents only one in ten of the population of the US, and less than $0.5 \%$ of the world's population.

This solipsism seems to me to have also largely defined the US perspective on 9/11. This is not to underestimate the traumatic effect of $9 / 11$, but to suggest that, seen in perspective, it is not quite cataclysmic, and certainly it is not the first, nor the most appalling anthropogenic catastrophe to befall the human race. A number of such catastrophes were pushing their ghastly calculus into the hundreds of thousands in the "undeveloped world" even as 9/11 drowned out all other calamities. Other times as well as other places have endured infinitely more horrific evidence of our capacity for mass destruction of human life. This was not even an unprecedented unannounced peacetime assault on US citizens. The most notorious caused the death of around 2400, wounding a further 1280 . This is pretty much of the order of the World Trade Centre fatalities (around 2600), with similarly massive destruction of material: 12 naval ships sunk and damaged and nearly 200 aircraft destroyed, at Pearl Harbour on December 7 1941. Of course, and I emphasise this, no catastrophe is exactly the same as any other, but they have sufficient points in common to invite a more careful elucidation of the differences, from which we may draw instructive conclusions not available to us if $9 / 11$ is so starkly exceptionalised. And the way to do that is to break out of the historically depthless synchronic approach into a diachronic one. If we want to assess what was transformingly distinctive about cultural (including musical) responses to 9/11, a comparison with those elicited by other catastrophes in other times and places would be highly instructive. Perspective. As Auden, looking at Bruegel's Icarus reflected:

About suffering, they were never wrong,

The Old Masters: how well they understood

Its human position; how it takes place

While someone else is eating or opening a window, or just walking dully along. 


\title{
The Politics of Post-9/11 Music: Sound, Trauma, and the Music Industry in the Time of Terror
}

\author{
Joseph P. Fisher and Brian Flota (Eds) \\ Farnham, Surrey, UK: Ashgate, 2011 \\ ISBN: $9781409427841(\mathrm{HB})$ \\ RRP: \$99.95 (USD)
}

\author{
Bruce Johnson \\ University of Turku, Finland \\ Bruce.Johnson@utu.fi
}

It would squander space to list the contents of this collection, since they and the Introduction can be read online at:

http://www.ashgate.com/default.aspx?page $=637 \&$ calctitle $=1 \&$ pageSubject $=414 \&$ title id=10895\&edition id=14358.

Given the hydra head of the music industry it is gratifying to see such a collection bringing a cross-disciplinary perspective that appears to go beyond academic to professional and journalistic discourses. Inevitably, the result is a curate's egg. In spite of the words 'Post 9/11 Music' in the title, much of this collection is not really about music developments that postdate 9/11 and which might be considered to have been caused by that appalling event. The subtitle's phrase 'in the age of terror' opens more historical leeway, if at the expense of precision - there have after all been other 'ages of terror', a circumstance rather elided in the use of the exceptionalist and solipsistic definite article. Of this, more below.

Among the most instructive chapters are those which address changes in media technologies and music, largely the brief of the three chapters in Part 1 . While there is no evidence that these changes would not have proceeded without $9 / 11$, it is certainly arguable that they are linked closely to, or deployed in the service of, a public anxiety increased dramatically by that event, as for example the production of the video game America's Army. When we turn to the contemporary sensibilities, what might be called the 'mentalité' of the 'age of terror' however, there seems to be rather tenuous evidence of profound changes. 9/11 itself is not actually pivotal in many of the developments that are discussed, which were responses to other events both before and after, such as musical interventions in the Bush election campaign of 2004 (Rock Against Bush); that is, responses not to $9 / 11$ but to the incompetence of Bush's responses to it. Or they were forms of consciousness and practice that in fact predated 2001, such as disillusionment with what may be called the American Dream (see early twentieth century writers like Fitzgerald and West, as well as a very extensive library of US popular song). For example, the emergence of goth-punk, for which the claim that it manifests "a generational loss of innocence caused by the war on terror" (2011: 150), seems clearly anachronistic. Similarly, the militarisation of everyday life referred to in Chapter 1 certainly did not begin post-2001, but characterised many 
regimes from ancient times (Sparta) to, for example, the Third Reich. Likewise, the suggestion that "the first example of the hybridization of music video and military recruitment" (14) was the video "Citizen/Soldier" (14) is simply a statement about the application of a modern technology to an ancient nexus. Music has always accompanied recruitment campaigns; even the Pied Piper was almost certainly a member of a special cadre of military recruiters using theatrical costumes and music. The discussion of the "technostalgic" re-emergence of cassette technology (43-56) was fascinating. But the author himself dates the trend from 1995, and while it might have acquired a new resonance after 2001, it was hardly a product of it. There is also an argument that the first word in Improvised Explosive Device - IED - (instead of, for example "home-made") reflects a negative valency that links it to the suspicion in which jazz was once held, because they are both associated with subversion (yet we are also told that a US military slogan is "adapt, improvise, overcome"). But the author also notes that the first use of the term IED was at least as far back as 1940, so it is not clear how an event in 2001 is seminal here. That valency incidentally is allegedly fortified by the fact that the Twin Towers was "from a conventional viewpoint an improvisational" (80) attack, though five lines later it is described as "carefully planned". I know of no evidence that it was ever seriously regarded otherwise.

This is really a collection of essays, many of them extremely instructive, on aspects of popular music in the twenty-first century (and sometimes much earlier). And as someone who has extensively researched and published on music and trauma, I was surprised at how little reference was made to the latter, given the title. Sometimes 9/11 and its consequences do provide a persuasive hook to hang them on, as in Kathryn Wright's discussion of Nine Inch Nails and the Patriot Act. Also outstanding are Steve Waksman's detailed and judicious analysis of the use of heavy metal in films about the war in Iraq and Gerritt Roessler's discussion of Christian punk rock in its aftermath convincingly traces a shift in consciousness, using the band Underoath as a case study. It is interesting that these studies are anchored securely in specific texts, which act as a check, in all senses, on generalisation and hyperbole. And it is equally of interest that one of the conclusions arising from Roessler's study, and also to a significant extent from those of Jeffrey Roessner and Matthew Siblo on punk and indie rock, is that pop largely failed to register $9 / 11(115-6,129)$. Maybe here is the answer to the question of why the focus of this collection is so diffuse in relation to the event its title centralises. As Roessler suggests, "The established cultural and political institutions failed to create a homogenous response to $9 / 11$ precisely because homogeneity is not a quality of mainstream culture" (181).

It is as though mainstream US culture no longer seems to be able to draw on the kind of fully agreed history that produces something approaching the national consciousness that appears to unite a community in the face of real or assumed adversity - like Germany from the mid-1930s or Britain or the US during WW2. Mention of the lack of a sense of history, a cultural solipsism, takes me back to the opening comments. I certainly do not want to make the absurd claim that because there have been worse things than 9/11 we should not be talking about it. It did have an impact that requires notice. My difficulty lies with the frequent absence of perspective which leads to misleading and ahistorical claims and generalisations. Apart from examples already cited, the claims that if music is not online in the 21st century "it does not exist for popular culture" (31), and that "music is no longer centred in itself, but rather in the device on which it plays" (41) overlook the massive amount of live music-making that takes place every day - and who are those people making and listening to music on videos of concerts on Youtube? This is what I mean by solipsism - the mistaken assumption that the world is comprehended fully within my own wired up horizons. To exemplify, in 2006 I had reason to discover that since the introduction of the iPod in 2001, market leader Apple has shipped in excess of thirty million units. The figure is 
impressive, until it is remembered that this represents only one in ten of the population of the US, and less than $0.5 \%$ of the world's population.

This solipsism seems to me to have also largely defined the US perspective on 9/11. This is not to underestimate the traumatic effect of $9 / 11$, but to suggest that, seen in perspective, it is not quite cataclysmic, and certainly it is not the first, nor the most appalling anthropogenic catastrophe to befall the human race. A number of such catastrophes were pushing their ghastly calculus into the hundreds of thousands in the "undeveloped world" even as 9/11 drowned out all other calamities. Other times as well as other places have endured infinitely more horrific evidence of our capacity for mass destruction of human life. This was not even an unprecedented unannounced peacetime assault on US citizens. The most notorious caused the death of around 2400, wounding a further 1280 . This is pretty much of the order of the World Trade Centre fatalities (around 2600), with similarly massive destruction of material: 12 naval ships sunk and damaged and nearly 200 aircraft destroyed, at Pearl Harbour on December 7 1941. Of course, and I emphasise this, no catastrophe is exactly the same as any other, but they have sufficient points in common to invite a more careful elucidation of the differences, from which we may draw instructive conclusions not available to us if $9 / 11$ is so starkly exceptionalised. And the way to do that is to break out of the historically depthless synchronic approach into a diachronic one. If we want to assess what was transformingly distinctive about cultural (including musical) responses to 9/11, a comparison with those elicited by other catastrophes in other times and places would be highly instructive. Perspective. As Auden, looking at Bruegel's Icarus reflected:

About suffering, they were never wrong,

The Old Masters: how well they understood

Its human position; how it takes place

While someone else is eating or opening a window, or just walking dully along. 